\title{
Prevalence of Human Papillomavirus Type 16 Variants in the Federal District, Central Brazil
}

\author{
Márcio R Cruz/ ${ }^{++}$, Daniela M Cerqueira, Waldenor B Cruz, Geni NL Camara*, \\ Marcelo M Brígido, Evandro 0 Silva**, Luciano GS Carvalho***, Cláudia RF Martins/+
}

\author{
Instituto de Biologia, Universidade de Brasília, ICC Sul, 70919-900 Brasília, DF, Brasil *Agência de Vigilância Sanitária, \\ Ministério da Saúde, Brasília, DF, Brasil **Hospital Regional da Ceilândia, Ceilândia, DF, Brasil ***Hospital de Base do \\ Distrito Federal, Brasília, DF, Brasil
}

We report the prevalence of human papillomavirus type 16 (HPV-16) variants in women with cervical lesions from the Federal District, Central Brazil. We analyzed 34 HPV-16 samples, identifying the sequence variations of E6 and L1 genes and correlating variant frequency with disease status. The most prevalent HPV-16 variant was the European (50\%), followed by Asian-American (41.2\%), African-1 (5.9\%), and African-2 (2.9\%). European and non-European variants appeared in equal frequencies among the cytological types of lesions - atypical squamous or glandular cells of undetermined significance, cytological alterations suggesting HPV infection, cervical intraepithelial neoplasias, squamous cell carcinoma, and adenocarcinoma.

Key words: human papillomavirus type 16 - variants - Federal District, Brazil

Human papillomaviruses (HPVs) have been consistently associated with invasive cervical carcinoma (ICC) and cervical intraepithelial neoplasias (CINs) (Lehtinen et al. 2001, Matsukura \& Sugaset 2001). Worldwide, HPV-16 is considered the most prevalent of the more than 20 different HPV types associated with cervical lesions (Bosch et al. 1995). Within an HPV type, variants are defined by nucleotide substitutions of up to $2 \%$ in E6 and L1 genes and by up to $5 \%$ in the LCR (Chan et al. 1995). HPV-16 variants can be clustered in 5 groups: African-1, African2, Asian, Asian-American, and European (Stewart et al. 1996, Yamada et al. 1997). The sequence considered to be the reference, mentioned as the prototype (Seedorf et al. 1985), belongs to the European branch.

The purpose of the present study is to describe the prevalence of HPV-16 variants in cervical specimens from the Federal District, Central Brazil, as well as to investigate a possible differential variant associated pathogenicity in this population.

Thirty four HPV-16 variants were identified by polymerase chain reaction (PCR) amplification and automated sequencing of the MY09/MY11 (Bernard et al. 1994) L1 region and the entire E6 gene, amplified by primers E6A/ E6S (Gibco) (Wheeler et al. 1997). The same primers were

Financial support: Fundação de Apoio à Pesquisa do Distrito Federal and Fundação de Empreendimentos Científicos e Tecnológicos

${ }^{+}$Corresponding author. Fax: +55-61-272.1793. E-mail: cmartins@unb.br

${ }^{++}$Fellowship from the Coordenação de Aperfeiçoamento de Pessoal de Nível Superior

Received 3 November 2003

Accepted 29 April 2004 used for automatically sequencing the 2 strands of the amplified products using a Megabace System (Amersham Pharmacia). The base positions of all sequences obtained were numbered after basic local alignment search tool (BLAST) analysis (Altschul et al. 1997), and the variant designation followed the classification of Wheeler et al. (1997).

The most prevalent HPV-16 variant was the European (17 out of $34,50 \%$ ), followed by the Asian-American (14 out of $34,41.2 \%$ ), African-1 (2 out of $34,5.9 \%$ ), and African-2 (1 out of $34,2.9 \%$ ). Only one of the European variants was an E-350G variant. HPV-16 non-European and European variants were detected at similar frequencies among the cytological types of lesions, revealing an uniform distribution (Table I). We identified one nucleotide substitution in an Asian-American variant (Bsb-81) that had not been reported previously by other authors. It occurred at position 80 (thymine to guanine) (Table I), between a TATA signal (from nucleotide 65 to 71 ) and the beginning of the E6 coding region (from nucleotide 83 to 559).

Considering all variants, 12 different point mutations were detected within the E6 segment, spanning nucleotides 31 and 683. Seven different point mutations were detected within the L1 segment, spanning nucleotides 6584 and 7035 (Table I). Altogether, 8 point mutations in 7 nucleotide positions generated amino acid changes in E6 and in L1 proteins (Table II).

In Brazil, similar to the prevalence of HPV-16 European variants in the Federal District (50\%), Villa et al. (2000) detected European variants in 54\% of the patients in São Paulo. However, in our study, the percentage of patients positive for Asian-American variants (41.2\%) was higher than that reported by other authors. Villa et al. (2000) detected Asian-American variants in $22 \%$ of the patients and Yamada et al. (1997), in an international study, de- 
TABLE I

Nucleotide correlation of human papillomavirus type 16 prototype and variants. The nucleotide positions are indicated vertically. Positions at which no variation was found are marked with traces, whereas a letter indicates a variant nucleotide at this position. Analyses according to Wheeler et al. (1997)

\begin{tabular}{|c|c|c|c|c|c|c|c|c|c|c|c|c|c|c|c|c|c|c|c|}
\hline \multirow[t]{3}{*}{ Variant } & \multicolumn{11}{|c|}{ E6 DNA sequence } & \multicolumn{7}{|c|}{ L1 DNA sequence } & \multirow[t]{2}{*}{$\mathrm{N}$} \\
\hline & & & & & & & & & & & & 6 & 6 & 6 & 6 & 6 & 6 & 6 & \\
\hline & & 1 & 1 & 1 & 1 & 2 & 2 & 3 & 3 & 4 & 5 & 6 & 7 & 8 & 8 & 8 & 9 & 9 & \\
\hline & 8 & 0 & 3 & 4 & 4 & 8 & 8 & 3 & 5 & 0 & 3 & 9 & 2 & 0 & 5 & 6 & 7 & 9 & \\
\hline & 0 & 9 & 2 & 3 & 5 & 6 & 9 & 5 & 0 & 3 & 2 & 5 & 1 & 3 & 4 & 5 & 0 & 4 & \\
\hline HPV-16R & $\mathrm{T}$ & $\mathrm{T}$ & G & $\mathrm{C}$ & $\mathrm{G}$ & $\mathrm{T}$ & A & $\mathrm{C}$ & $\mathrm{T}$ & A & A & A & G & A & $\mathrm{C}$ & $\mathrm{C}$ & $\mathrm{C}$ & $\mathrm{G}$ & \\
\hline E-P & - & - & - & - & - & - & - & - & - & - & - & - & - & - & - & - & - & - & 16 \\
\hline E-350G & - & - & - & - & - & - & - & - & $\mathrm{G}$ & - & - & - & - & - & - & - & - & - & 1 \\
\hline $\mathrm{AA}$ & - & - & - & - & $\mathrm{T}$ & $\mathrm{A}$ & $\mathrm{G}$ & $\mathrm{T}$ & G & - & G & $\mathrm{C}$ & A & $\mathrm{T}$ & $\mathrm{T}$ & $\mathrm{T}$ & $\mathrm{T}$ & A & 13 \\
\hline Af1 & - & - & $\mathrm{C}$ & G & $\mathrm{T}$ & A & G & $\mathrm{T}$ & - & - & - & - & A & - & $\mathrm{T}$ & - & $\mathrm{T}$ & A & 2 \\
\hline Af2 & - & $\mathrm{C}$ & $\mathrm{T}$ & $\mathrm{G}$ & $\mathrm{T}$ & A & $\mathrm{G}$ & $\mathrm{T}$ & - & $\mathrm{G}$ & - & $\mathrm{C}$ & A & - & $\mathrm{T}$ & $\mathrm{T}$ & $\mathrm{T}$ & A & 1 \\
\hline Bsb-81 & $\mathrm{G}$ & - & - & - & $\mathrm{T}$ & $\mathrm{A}$ & $\mathrm{G}$ & $\mathrm{T}$ & G & - & G & $\mathrm{C}$ & A & $\mathrm{T}$ & $\mathrm{T}$ & $\mathrm{T}$ & $\mathrm{T}$ & A & 1 \\
\hline
\end{tabular}

\section{TABLE II}

Amino acid correlation of human papillomavirus type 16 prototype and variants. The position of amino acid change is stated numerically. The letter preceding this number refers to the prototype amino acid, and the letter after it refers to its substitution

\begin{tabular}{lcc}
\hline & \multicolumn{2}{c}{ Mutation description } \\
\cline { 2 - 3 } Variant & \multicolumn{1}{c}{ E6 protein } & L1 protein \\
\hline E-350G & L83V & - \\
AA & Q14H, H78Y, L83V & T379P, T415S \\
Af-1 & R10T, Q14D, H78Y & - \\
Af-2 & R10I, Q14D, H78Y & T379P \\
\hline
\end{tabular}

tected Asian-American variants in $19.7 \%$ of the patients living in Central and South America.

Our results suggest that HPV-16 non-European variants do not represent an additional factor associated with increased occurrence of high grade cervical lesions in the studied population, as European and non-European variants appeared in equal frequencies among the cytological types of lesions. Nindl et al. (1999) also did not find any correlation between variants and severity of the lesion.

\section{ACKNOWLEDGEMENTS}

To John Penney, for reviewing this manuscript.

\section{REFERENCES}

Altschul SF, Madden TL, Schäffer AA, Zhang J, Zhang Z, Miller W, Lipman DJ 1997. Gapped BLAST and PSI-BLAST: a new generation of protein database search programs. Nucleic Acids Res 25: 3389-3402.

Bernard HU, Chan SY, Manos MM, Ong CK, Villa LL, Delius H, Peyton DL, Bauer HM, Wheller CM 1994. Identification and assessment of known and novel human papillomaviruses by polymerase chain reaction amplification, restriction fragment length polymorphisms, nucleotide sequence and phylogenetic algorithms. J Infect Dis 170: 1077-1085.

Bosch FX, Manos MM, Munoz N, Sherman M, Jansen AM,
Peto J, Schiffman MH, Moreno V, Kurman R, Shah KY 1995. Prevalence of human papillomavirus in cervical cancer: a worldwide perspective. International biological study on cervical cancer (IBSCC) study group. J Natl Cancer Inst 87: 796-802.

Camara GNL, Cerqueira DM, Oliveira AP, Silva EO, Carvalho LGS, Martins CRF 2003. Prevalence of human papillomavirus types in women with pre-neoplastic and neoplastic cervical lesions in the Federal District of Brazil. Mem Inst Oswaldo Cruz 98: 879-883.

Chan SY, Delius H, Halpern AL, Bernard HU 1995. Analysis of genomic sequences of 95 papillomavirus types: uniting typing, phylogeny, and taxonomy. J Virol 69: 3074-3083.

Lehtinen M, Luukkaala T, Wallin KL, Paavonen J, Thoresen S, Dillner J, Hakama M 2001. Human papillomavirus infection, risk for subsequent development of cervical neoplasia and associated population attributable fraction. J Clin Virol 22: 117-124.

Matsukura T, Sugaset M 2001. Relationships between 80 human papillomavirus genotypes and different grades of cervical intraepithelial neoplasia: association and causality. Virology 283: 139-147.

Nindl I, Rindfleisch K, Lotz B, Schneider A, Dürst M 1999. Uniform distribution of HPV 16 E6 and E7 variants in patients with normal histology, cervical intra-epithelial neoplasia and cervical cancer. Int J Cancer 82: 203-207.

Seedorf K, Krämmer G, Dürst M, Suhai S, Röwekamp WG 1985. Human papillomavirus type 16 DNA sequence. Virology 145: 181-185.

Stewart ACM, Eriksson AM, Manos MM, Muñoz N, Bosch FX, Peto J, Wheeler CM 1996. Intratype variation in 12 human papillomavirus types: a worldwide perspective. $J$ Virol 70: 3127-3136.

Villa LL, Sichero L, Rahal P, Caballero O, Ferenczy A, Rohan T, Franco EL 2000. Molecular variants of human papillomavirus types 16 and 18 preferentially associated with cervical neoplasia. J Gen Virol 81: 2959-2968.

Wheeler CM, Yamada T, Hildesheim A, Jenison SA 1997. Human papillomavirus type 16 sequence variants: identification by E6 and L1 lineage-specific hybridization. J Clin Microbiol 35: 11-19.

Yamada T, Manos MM, Peto J, Greer CE, Muñoz N, Bosch FX, Wheeler CM 1997. Human papillomavirus type 16 sequence variation in cervical cancer: a worldwide perspective. J Virol 71: 2463-2472. 